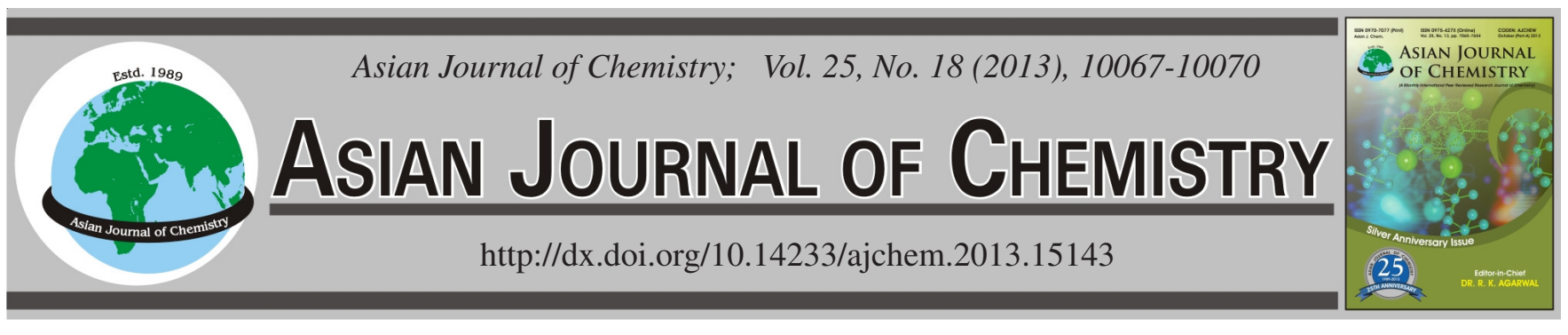

\title{
Preparation of Diamino-Bridged bis( $\beta$-Cyclodextrin)s and Their Application as Chiral Stationary Phases in HPLC
}

\author{
Y.X. Chang, B. Bai, L.M. Du*, X. Jing, C.F. Li and Y.L. Fu
}

Analytical and Testing Center, Shanxi Normal University, Linfen 041004, Shanxi Province, P.R. China

*Corresponding author: Tel/Fax: +86 357 2057969; E-mail: 1md@dns.sxnu.edu.cn

\begin{abstract}
Three diamino-bridged bis( $\beta$-cyclodextrin)s, namely 1,3-(aminomethyl)-benzylamine-bridged bis(6-amino-6-deoxy- $\beta$-cyclodextrin) (1), 4,4-diaminodiphenyl methano-bridged bis(6-amino-6-deoxy- $\beta$-cyclodextrin) (2) and 4,4 -ethylenedianiline-bridged bis(6-amino-6-deoxy$\beta$-cyclodextrin) (3), were prepared and used in the novel application as chiral stationary phases (CSPs) in HPLC. Their ability to separate 11 enantiomers was investigated using triethylammonium acetate buffer containing methanol as the mobile phase. All three chiral stationary phases, particularly chiral stationary phase-1 (CSP1), have better enantiomer separation efficiencies than the parent $\beta$-cyclodextrin. Therefore, the linker length between two cyclodextrin units is effective to enantioselectivity and the resolution ability decreases with increased linker length, which conforms with the molecular recognition ability.
\end{abstract}

Key Words: HPLC, Diamino-bridged bis( $\beta$-cyclodextrin)s, Chiral stationary phase, Enantiomer.

ᄂ - - - - - - - - - - - - - - - - - - - - - - - - -

\section{INTRODUCTION}

The enantiomeric forms of a drug can differ in potency, toxicity and behaviour in biological systems. Pure single enantiomers can be produced using different techniques ${ }^{1,2}$. Chiral high-performance liquid chromatography (HPLC) is a widely used technique for enantiomeric separation and analysis. The key to successful chiral HPLC is the development of highly selective chiral stationary phases (CSPs). Chiral chromatographic methods are particularly useful in the pharmaceutical industry.

Cyclodextrins (CDs) and their derivatives are widely used as CSPs to separate chiral compounds ${ }^{3}$. Native CDs can resolve some enantiomers, but $\mathrm{CD}$ derivatives can perform better. The chromatographic properties, chiral recognition ability, solubility and complex-forming capacity of CDs can be improved through derivation. Therefore, the range of enantiomeric compounds that can be separated using CDs is significantly expanding ${ }^{4-6}$. However, previous studies demonstrated that bis $(\beta-C D)$ s bind better and are more selective toward certain guest molecules than monomeric CDs. The improved properties of modified CDs are attributed to the cooperative two-point recognition that mimics the highly substratespecific binding of enzymes ${ }^{7-9}$. A variety of structurally diverse bis $(\beta-\mathrm{CD}) \mathrm{s}$ have been prepared to elucidate their complexation behaviour as well as the factors and mechanisms governing the multipoint recognition upon inclusion complexation ${ }^{10,11}$. Furthermore, bis( $\beta-\mathrm{CD})$ s used as CSPs in HPLC are rare.
In the present study, three diamino-bridged bis( $\beta-\mathrm{CD}) \mathrm{s}$, namely, 1,3-(aminomethyl)-benzyl amine-bridged bis(6amino-6-deoxy- $\beta$-CD) (1), 4,4-diaminodiphenylmethanobridged bis(6-amino-6-deoxy- $\beta$-CD) (2) and 4,4-ethylenedianiline-bridged bis(6-amino-6-deoxy- $\beta$-CD) (3), were grafted with silica gel and used as CSPs in HPLC. The enantiomeric separation abilities of the three CSPs in HPLC were investigated using 11 racemates. The short-chain-length bridged stationary phase is found to exhibit strong resolution ability for racemates compared with the parent $\beta-\mathrm{CD}$.

\section{EXPERIMENTAL}

Silica gel (particle size, $5 \mu \mathrm{m}$; pore size, $10 \mathrm{~nm}$; specific surface area, $400 \mathrm{~m}^{2} \mathrm{~g}^{-1}$ ) was supplied by Lanzhou Institute of Chemical Physics, Chinese Academy of Sciences. Reagentgrade $\beta$-cyclodextrin (Sinopharm Chemical Reagent Shanghai Co., Ltd.) was recrystallized twice from water and dried under a vacuum at $95^{\circ} \mathrm{C}$ for $24 \mathrm{~h}$ prior to use. $p$-Toluenesulfonyl was purchased from Kermel Chemical Reagent Tianjin Co., Ltd. (3-Glycidoxypropyl)-trimethoxysilane was obtained from Tokyo Chemical Industry Co., Ltd. (Tokyo, Japan). 1,3-(Aminomethyl)-benzylamine, 4,4-diaminodiphenylmethane and 4,4ethylenedianiline were purchased from Aldrich Co. 2-Phenyl1-propanol, mandelic acid and $\alpha$-methylbenzylamine were purchased from Fluka Co. Metoprolol tartrate and pioglitazone were purchased from Dr. Ehrenstorfer GmbH. Ibuprofen, ketoprofen, cetirizine, naproxen, rapaglinide and loxoprofen 
were obtained from the Chinese National Institute for the Control of Pharmaceutical and Biological Products. N,NDimethylformamide was dried over calcium hydride for 2 days and then distilled under reduced pressure. The solvents used in the chromatographic experiments were HPLC grade. MilliQ water (Millipore, Bedford, MA, USA) was used throughout the experiments. All other organic solvents and chemical reagents were at least analytical reagent grade and from various commercial sources.

HPLC analyses were performed using a Waters 1525 binary HPLC pump, a manual injection valve model (7725i), a Waters 2489 UV-visible detector and a Waters chromatography working station Breeze 2. The detection wavelength was 254 $\mathrm{nm}$. Stainless steel tubes $(250 \mathrm{~mm} \times 4.6 \mathrm{~mm}$ i.d.; Alltech, USA) were packed with packing materials by a conventional highpressure slurry packing technique using a model 1666 slurry packer (Alltech, USA). ${ }^{1} \mathrm{H}$ NMR spectra were recorded on a DRX-600MHz (Bruker, $600 \mathrm{MHz}$ ) spectrometer. FT-IR spectra were obtained on a Bruker FT-IR system. The elemental analyzer used was a Vario El Cube (German Elementar).

Preparation of diamino-bridged bis $(\boldsymbol{\beta}-\mathrm{CD})$ stationary phases: Mono[6-O-( $p$-toluenesulfonyl $)]-\beta-C D$ was prepared from $\beta$-CD and $p$-toluenesulfonyl chloride in an aqueous alkaline solution according to literature ${ }^{12} \cdot 1,3$-(Aminomethyl)benzylamine-bridged bis(6-amino-6-deoxy- $\beta$-CD) (1) was synthesized according to literature ${ }^{13}$. The preparation process is briefly described as follows. Under the protection of nitrogen, 1,3-(aminomethyl)-benzylamine $(2.0 \mathrm{mmol})$ and mono[6-O( $p$-toluenesulfonyl)]- $\beta$-CD (4.2 mmol) were dissolved in anhydrous DMF $(40 \mathrm{~mL})$ and the reaction mixture was stirred for $72 \mathrm{~h}$ at $85-90^{\circ} \mathrm{C}$. The reaction solution was then evaporated to dryness under reduced pressure. The residue was dissolved in water and the resultant solution was poured into acetone to obtain a brown-yellow precipitate. The crude product was collected by filtration and purified on Sephadex G-25 with Milli-Q water as eluent to obtain the pure sample. 4,4-Diaminodiphenylmethano-bridged bis(6-amino-6-deoxy- $\beta$-CD) (2) and 4,4-ethylenedianiline-bridged bis(6-amino-6-deoxy- $\beta$-CD) (3) were prepared similarly as 3-(aminomethyl)-benzylaminebridged bis(6-amino-6-deoxy- $\beta$-CD). Their IR spectra and ${ }^{1} \mathrm{H}$ NMR data conformed with those in literature ${ }^{13}$.

Diamino-bridged bis $(\beta-\mathrm{CD})$ stationary phases was prepared according to a previous procedure with some modifications ${ }^{14}$. Exactly $6 \mathrm{~g}$ of diamino-bridged bis( $\beta$-CD)s was dissolved in $100 \mathrm{~mL}$ of anhydrous DMF, to which $1.0 \mathrm{~g}$ of sodium hydride was added. The mixture was stirred for $0.5 \mathrm{~h}$ at room temperature. After removing unreacted sodium hydride by filtration, $2 \mathrm{~mL}$ of (3-glycidoxypropyl)-trimethoxysilane was added to the filtrate. The mixture was continuously stirred at $85-90{ }^{\circ} \mathrm{C}$ for $5 \mathrm{~h}$ under a dry nitrogen atmosphere and then cooled to room temperature. About $5 \mathrm{~g}$ of activated silica gel was added and the reaction mixture was allowed to react for $24 \mathrm{~h}$ at 110 $120^{\circ} \mathrm{C}$. The obtained solid was filtered and washed with DMF, water, methanol and acetone. The silica was dried at $60^{\circ} \mathrm{C}$ for $6 \mathrm{~h}$ in vacuo. Finally, diamino-bridged bis( $\beta$-CD)-bonded stationary phases (CSP1, CSP2 and CSP3 corresponding to compounds $\mathbf{1}, \mathbf{2}$ and $\mathbf{3}$, respectively) were obtained. Their FTIR spectra $(\mathrm{KBr})$ feature the following peaks $\left(\mathrm{V} / \mathrm{cm}^{-1}\right): 3450$ (O-H, N-H), $2920(\mathrm{C}-\mathrm{H})$, as well as 1630, 1530 and $1420(\mathrm{C}=\mathrm{C}$ aromatic ring). The amounts of bonded diamino-bridged bis( $\beta$ $\mathrm{CD})$ s were estimated from the results of elemental analyses as follows (\%): CSP1, C, 14.45; H, 2.54; N, 0.70; CSP2, C, 13.94; $\mathrm{H}, 2.56 ; \mathrm{N}, 0.77$ and CSP3, C, 14.23; H, 2.52; N, 0.72. The corresponding amounts were $c a .136 .8,119.8$ and $121.2 \mu \mathrm{mol}$ $\mathrm{g}^{-1}$, respectively.

A $\beta$-cyclodextrin stationary phase (CD-CSP) was similarly prepared. The result of elemental analysis was as follows (\%): C, $12.24 ; \mathrm{H}, 2.24 ; \mathrm{N}, 0.31$.

Methods: The packing materials were dispersed into isopropyl alcohol and packed into a stainless steel column (250 $\mathrm{mm} \times 4.6 \mathrm{~mm}$ i.d.) with a methanol solution at $40 \mathrm{MPa}$ by a slurry packing technique. The column was rinsed online with methanol for $5 \mathrm{~h}$ and then equilibrated with methanol/water as the eluent at a flow rate of $0.5 \mathrm{~mL} \mathrm{~min}^{-1}$ until a stable baseline was obtained. The mobile phases used were mixtures of methanol/ triethylammonium acetate buffer $(0.1 \%, \mathrm{v} / \mathrm{v}, \mathrm{pH} 4.1)$ with different volume ratios. The flow rate of the mobile phase was $0.5 \mathrm{~mL} \mathrm{~min}^{-1}$ at $30{ }^{\circ} \mathrm{C}$. All test solutes were detected at 254 $\mathrm{nm}$. Methanol was used to dissolve test samples. The baseline perturbation resulting from the injection of the mobile phase was used as the void volume marker $\left(\mathrm{t}_{0}\right)$.

\section{RESULTS AND DISCUSSION}

Eleven racemates [ibuprofen (1), ketoprofen (2), cetirizine (3), 2-phenyl-1-propanol (4), mandelic acid (5), $\alpha$-methylbenzylamine (6), metoprolol tartrate (7), naproxen (8), pioglitazone (9), rapaglinide (10) and loxoprofen (11)] (Fig. 1) were separated from CD-CSP. Their retention factor $\left(\mathrm{k}_{1}^{\prime}\right)$ for the first eluted enantiomer and resolution $\left(\mathrm{R}_{\mathrm{S}}\right)$ obtained using the CSP are summarized in Table- 1 . Six racemates can be partially separated, whereas the other five racemates can be completely separated.

The results of the chiral resolution of racemates 1-11 on CSP1-3 are also summarized in Table-1. Cetirizine (3), mandelic acid (5), $\alpha$-methylbenzylamine (6), metoprolol tartrate (7) and naproxen (8), which can be completely resolved on CD-CSP, were all completely resolved on CSP1-3. Ibuprofen (1), ketoprofen (2) and 2-phenyl-1-propanol (4), which can only be partially separated on CD-CSP, were completely separated on CSP1. Ibuprofen (1) and ketoprofen (2) also obtained better resolution on CSP2 and CSP3. Pioglitazone (9) and loxoprofen (11), which can be partially separated on CD-CSP and CSP1, cannot be resolved on CSP3. Loxoprofen (11) can be partially separated on CSP2. Rapaglinide (10) can be partially separated on CD-CSP but not on CSP1-3. This may be due to the fact that one end steric hindrance of Rapaglinide (10) is relatively large. The molecule of Rapaglinide (10) can not enter the cavity of bis( $\beta-C D)$ s. Among these CSPs, CSP1 produced the best results. CD-CSP, CSP2 and CSP3 resulted in relatively good chiral recognition. Thus, the order of resolution of these CSPs toward the samples was CSP1 > CD-CSP > CSP2 > CSP3.

Fig. 2 shows the chromatograms obtained from ibuprofen (1) on CD-CSP1 and CSP1-3. Only partial separation was achieved on CD-CSP, whereas complete resolution was achieved on CSP1. Ibuprofen (1) was also relatively highly resolved on CSP2 and CSP3. The best resolution is shown in Fig. 2 (B). Fig. 2(A) shows lower resolution $\left(R_{S}\right)$ values. 


\begin{tabular}{|c|c|c|c|c|c|c|c|c|c|c|c|c|}
\hline \multirow{3}{*}{ Racemates } & \multicolumn{11}{|c|}{$\begin{array}{c}\text { TABLE-1 } \\
\text { TYPICAL ENANTIOSEPARATION DATA FOR RACEMATES IN CYCLODEXTRIN AND } \\
\text { DIAMINO-BRIDGED } b i s(\beta-C D) \text { sCHIRAL STATIONARY PHASES (CSPs) }\end{array}$} & \\
\hline & \multicolumn{3}{|c|}{ CD-CSP } & \multicolumn{3}{|c|}{ CSP1 } & \multicolumn{3}{|c|}{ CSP2 } & \multicolumn{3}{|c|}{ CSP3 } \\
\hline & Mobilephase & $\mathrm{k}_{1}{ }^{\prime}$ & $\mathrm{R}_{\mathrm{s}}$ & Mobilephase & $\mathrm{k}_{1}{ }^{\prime}$ & $\mathrm{R}_{\mathrm{s}}$ & Mobilephase & $\mathrm{k}_{1}{ }^{\prime}$ & $\mathrm{R}_{\mathrm{s}}$ & Mobilephase & $\mathrm{k}_{1}{ }^{\prime}$ & $\mathrm{R}_{\mathrm{s}}$ \\
\hline 1 & $45: 05$ & 1.02 & 0.81 & $40: 10$ & 1.17 & 2.21 & $45: 05$ & 0.85 & 1.34 & $45: 05$ & 0.67 & 1.23 \\
\hline 2 & 40: 10 & 0.58 & 0.68 & $30: 20$ & 1.42 & 2.44 & $30: 20$ & 1.34 & 2.78 & $30: 20$ & 1.00 & 2.02 \\
\hline 3 & 40: 10 & 0.28 & 2.36 & 40: 10 & 0.24 & 2.48 & $35: 15$ & 0.18 & 2.26 & $45: 05$ & 0.36 & 2.52 \\
\hline 4 & $35: 15$ & 0.82 & 1.26 & $35: 15$ & 0.78 & 1.57 & $30: 20$ & 1.00 & 1.52 & $30: 20$ & 0.76 & 0.86 \\
\hline 5 & $30: 20$ & 0.78 & 1.67 & $30: 20$ & 0.74 & 3.83 & $30: 20$ & 0.75 & 3.11 & $30: 20$ & 0.62 & 2.10 \\
\hline 6 & $30: 20$ & 0.18 & 2.62 & $30: 20$ & 0.23 & 2.68 & $30: 20$ & 0.30 & 2.58 & $30: 20$ & 0.31 & 2.20 \\
\hline 7 & $30: 20$ & 0.16 & 2.46 & $30: 20$ & 0.21 & 2.53 & $30: 20$ & 0.25 & 2.44 & $30: 20$ & 0.23 & 2.38 \\
\hline 8 & $30: 20$ & 1.72 & 1.54 & $30: 20$ & 1.44 & 2.18 & $30: 20$ & 1.40 & 2.20 & $30: 20$ & 1.06 & 1.63 \\
\hline 9 & 40:10 & 0.26 & 0.60 & $40: 10$ & 0.33 & 0.62 & $40: 10$ & 0.47 & 0.00 & $40: 10$ & 0.36 & 0.00 \\
\hline 10 & 40:10 & 0.23 & 0.66 & 40:10 & 0.36 & 0.00 & $40: 10$ & 0.51 & 0.00 & $40: 10$ & 0.47 & 0.00 \\
\hline 11 & 40:10 & 0.89 & 0.61 & 40:10 & 0.44 & 0.60 & $40: 10$ & 0.81 & 0.83 & $40: 10$ & 0.47 & 0.00 \\
\hline
\end{tabular}

The mobile phases used were mixtures of methanol/triethylammonium acetate buffer $(0.1 \%, \mathrm{v} / \mathrm{v}, \mathrm{pH} 4.1)$ by different volume ratios. $\mathrm{k}_{1}$ 'is the retentionfactor for the enantiomer eluted out first, ois the separation factorand $\mathrm{R}_{\mathrm{S}}$ is theresolution.<smiles>CC(C)Cc1ccc(C(C)C(=O)O)cc1</smiles>

(1)<smiles>CC(C(=O)O)c1cccc(C(=O)c2ccccc2)c1</smiles>

(2)<smiles>O=C(O)COCCN1CCN(c2cccc(-c3ccc(Cl)cc3)c2)CC1</smiles>

(3)<smiles>CC(CCO)c1ccccc1</smiles>

(4)<smiles>O=C(CO)C(O)c1ccccc1</smiles>

(5)<smiles>CC(N)c1ccccc1</smiles>

(6)<smiles>CC(C)NCC(O)COc1ccc(CCC=O)cc1</smiles>

(7)<smiles>CC(C(=O)O)c1ccc2cc(C=O)ccc2c1</smiles>

(8)<smiles>CCc1ccc(CCOc2ccc(CC3SC(=O)NC3=O)cc2)nc1</smiles>

(9)<smiles>CCOc1cc(CC(=O)NC(CC(C)C)c2ccccc2N2CCCCC2)ccc1C(=O)O</smiles>

(10)<smiles>CC(C(=O)O)c1cccc(CC2CCCC2=O)c1</smiles>

(11)

Fig. 1. Molecular structures of racemates 1-11

Chiral recognition is a result of the steric fit of the solute molecule conformation in the chiral helical groove as well as the conformation of solute molecule, dispersion, dipoledipole and hydrogen-bond interactions with the $\mathrm{NH}, \mathrm{OH}$ and phenyl groups of diamino-bridged bis $(\beta-\mathrm{CD}) \mathrm{s}^{15}$. In this study, the aromatic diamines enhanced the hydrophobicity of the microenvironment and adjusted the dimension of the hydrophobic cavity of $\beta-\mathrm{CD}$. The structure, length and flexibility of the linker can influence the steric fit result. The two linked $\mathrm{CD}$ units cooperatively bound to the molecule. The linker length between two CD units is influential to enantioselectivity. The resolution ability decreased with increased linker length, which conforms with the molecular recognition ability ${ }^{13}$. However, the influence of the chiral microenvironment on the chiral properties of the chromatographic systems is far from being understood.

\section{Conclusion}

Diamino-bridged bis( $\beta$-cyclodextrin)s were grafted with silica gel and used as chiral stationary phases in HPLC. The resulting chiral stationary phases exhibited good separation abilities for racemates. The resolution ability decreased with increased linker length of $\beta$-cyclodextrin $(\beta-C D)$ dimers. Short-chain-length bridged stationary phases had strong resolution ability for racemates. Bridged bis $(\beta$-cyclodextrin)s linked by an aromatic diamine significantly increased the resolution ability of the parent $\beta$-cyclodextrin. Therefore, the application range of diamino-bridged bis( $\beta$-cyclodextrin)s as newly prepared chromatographic chiral stationary phases in HPLC is extended. 

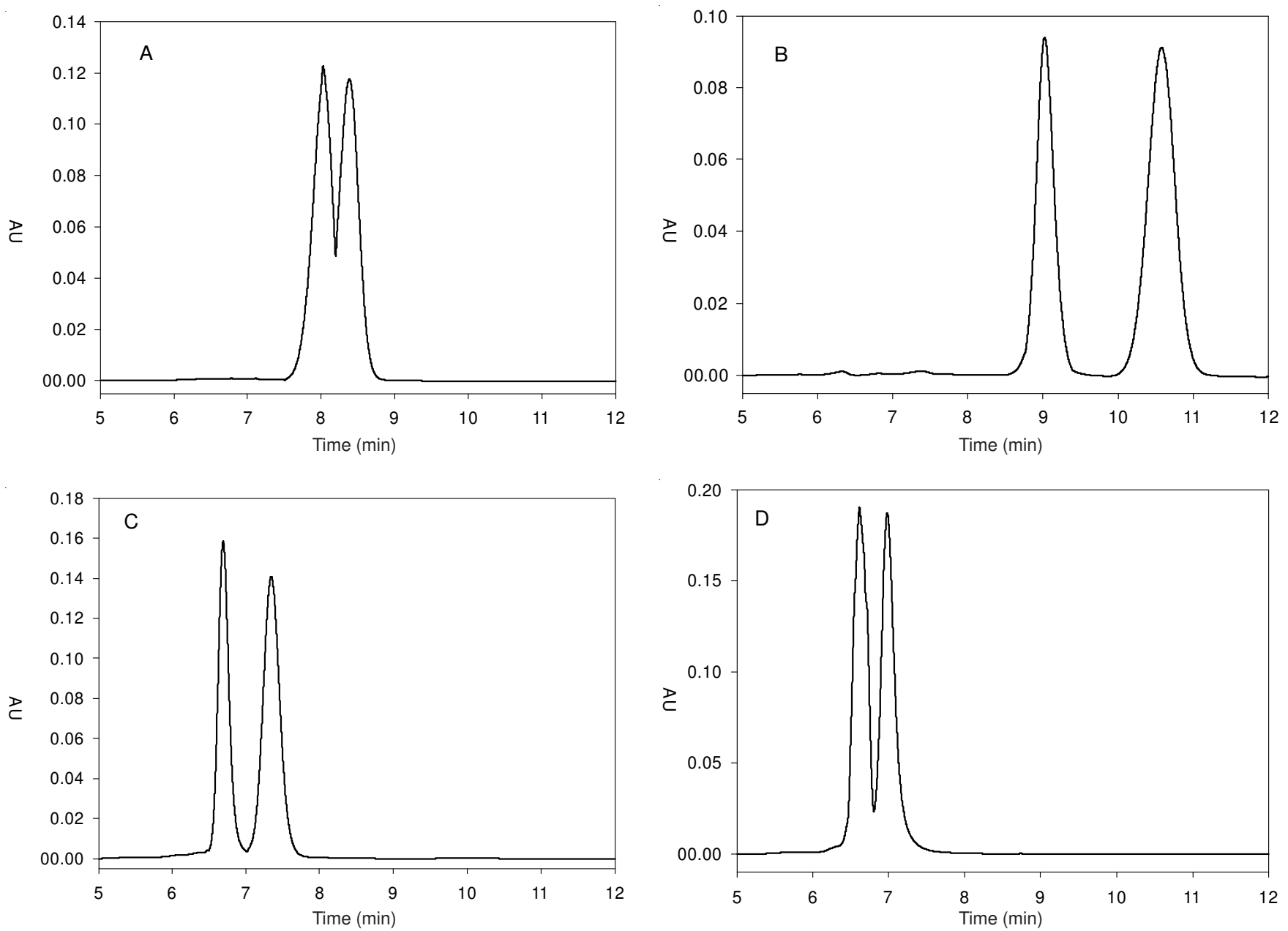

Fig. 2. Enantioseparation chromatograms of ibuprofen (1) (A) on CD-CSP; (B) on CSP1; (C) on CSP2; (D) on CSP3. HPLC conditions: silica gel $5 \mu \mathrm{m}$; column size: $250 \mathrm{~mm} \times 4.6 \mathrm{~mm}$; flow rate: $0.5 \mathrm{~mL} \mathrm{~min}{ }^{-1}$; temperature: $30{ }^{\circ} \mathrm{C}$; UV detection: $254 \mathrm{~nm}$

\section{ACKNOWLEDGEMENTS}

This work was supported by the National Natural Science Foundation of China (No. 21171110), the Research Fund for the Doctoral Program of Higher Education of China (No. 20091404110001).

\section{REFERENCES}

1. F.K. Glówka and M. Karazniewicz, J. Chromatogr. A, 1032, 219 (2004).

2. J. Qiu, Q. Wang, Z. Zhou and S. Yang, Asian J. Chem., 21, 6095 (2009).

3. R.Q. Wang, T.T. Ong, W.H. Tang and S.C. Ng, Anal. Chim. Acta, 718, 121 (2012)

4. F. Bressolle, M. Audran, T.N. Pham and J.J. Vallon, J. Chromatogr. B; Analyt. Technol. Biomed. Life Sci., 687, 303 (1996).

5. X.Y. Shi, M. Wang, G.R. Chen, R.N. Fu and J.L. Gu, Anal. Chim. Acta, 445, 221 (2001).

6. X.H. Lai, W.H. Tang and S.C. Ng, J. Chromatogr. A, 1218, 5597 (2011).
7. R. Breslow, Z. Yang, R. Ching, G. Trojandt and F. Odobel, J. Am. Chem. Soc., 120, 3536 (1998).

8. J.J. Michels, J. Huskens and D.N. Reinhoudt, J. Am. Chem. Soc., 124, 2056 (2002).

9. J. Wang, D.T. Pham, T.W. Kee, S.N. Clafton, X. Guo, P. Clements, S.F. Lincoln, R.K. Prudhomme and C.J. Easton, Macromolecules, 44, 9782 (2011).

10. S.H. Chiu, D.C. Myles, R.L. Garrell and J.F. Stoddart, J. Org. Chem., 65, 2792 (2000).

11. J.M. Benito, M. Gómez-García, C. Ortiz Mellet, I. Baussanne, J. Defaye and J.M. García Fernández, J. Am. Chem. Soc., 126, 10355 (2004).

12. R.C. Petter, J.S. Salek, C.T. Sikorski, G. Kumaravel and F.T. Lin, J. Am. Chem. Soc., 112, 3860 (1990).

13. Y. Zhao, X.Q. Liu, J. Gu, L.Q. Wang, H.Y. Zhu, R. Huang, Y.F. Wang and Z.M. Yang, J. Phys. Org. Chem., 21, 440 (2008).

14. D.W. Armstrong, A.M. Stalcup, M.L. Hilton, J.D. Duncan, J.R. Faulkner and S.C. Chang, Anal. Chem., 62, 1610 (1990).

15. M. Lämmerhofer, J. Chromatogr. A, 1217, 814 (2010). 